\title{
Characterization of Listeria monocytogenes Originating from the Spanish Meat-Processing Chain
}

\author{
Rosa Capita ${ }^{1,2}$, Amanda Felices-Mercado ${ }^{1}$, Camino García-Fernández ${ }^{1,2}$ and \\ Carlos Alonso-Calleja 1,2,* \\ 1 Department of Food Hygiene and Technology, Veterinary Faculty, University of León, E-24071 León, Spain; \\ rosa.capita@unileon.es (R.C.); afelim00@estudiantes.unileon.es (A.F.-M.); mc.garcia@unileon.es (C.G.-F.) \\ 2 Institute of Food Science and Technology, University of León, E-24071 León, Spain \\ * Correspondence: carlos.alonso.calleja@unileon.es; Tel.: +34-987-291000 (ext. 5633); Fax: +34-987-293073
}

Received: 1 August 2019; Accepted: 18 October 2019; Published: 3 November 2019

\begin{abstract}
Using agglutination techniques, 118 Listeria monocytogenes isolates from red meat and poultry were serotyped. Strains were ascribed to the serotypes $4 \mathrm{~b} / 4 \mathrm{e}(44.1 \%$ of the strains), $1 / 2$ (a, b or c; $28.0 \%$ ), $4 \mathrm{c}(6.8 \%), 4 \mathrm{~d} / 4 \mathrm{e}(5.9 \%)$ and $3(\mathrm{a}, \mathrm{b}$ or $\mathrm{c} ; 2.5 \%)$. Among these are the serotypes most frequently involved in cases of human listeriosis. The susceptibility of 72 strains to 26 antibiotics of clinical importance was determined by disc diffusion (Clinical and Laboratory Standards Institute; CLSI). High levels of resistance were observed to cefoxitin $(77.8 \%$ of the strains showed resistance), cefotaxime $(62.5 \%)$, cefepime $(73.6 \%)$, nalidixic acid $(97.2 \%)$, nitrofurantoin $(51.4 \%)$ and oxacillin $(93.1 \%)$. Less than $3 \%$ of the strains showed resistance to the antibiotic classes used in human listeriosis therapy (i.e., ampicillin, gentamicin, rifampicin, chloramphenicol, enrofloxacin, vancomycin, trimethoprim-sulfamethoxazole, erythromycin, and tetracycline). The influence of species and serotype on the growth kinetics (modified Gompertz equation) and on the adhesion ability (crystal violet staining) of nine isolates of L. monocytogenes (serotypes $1 / 2 \mathrm{a}, 1 / 2 \mathrm{~b}, 1 / 2 \mathrm{c}, 3 \mathrm{a}, 3 \mathrm{~b}, 3 \mathrm{c}, 4 \mathrm{a}, 4 \mathrm{~b}$, and $4 \mathrm{~d}$ ), and one strain of Listeria ivanovii were investigated. The maximum growth rate $\left(\Delta \mathrm{OD}_{420}-580 / \mathrm{h}\right)$ varied between $0.073 \pm 0.018$ (L. monocytogenes $1 / 2 \mathrm{a}$ ) and $0.396 \pm 0.026$ (L. monocytogenes $4 \mathrm{~b}$ ). The isolates of L. monocytogenes belonging to serotypes $3 \mathrm{a}$ and $4 \mathrm{a}$, as well as $L$. ivanovii, showed a greater $(p<0.05)$ biofilm-forming ability than did the remaining strains, including those that belong to the serotypes commonly implied in human listeriosis $(1 / 2 a, 1 / 2 b, 1 / 2 c$ and $4 b)$. The need for training in good hygiene practices during the handling of meat and poultry is highlighted to reduce the risk of human listeriosis.
\end{abstract}

Keywords: Listeria monocytogenes; meat; serotypes; antibiotic resistance; growth kinetic parameters; biofilm

\section{Introduction}

Twenty species of Listeria have been described [1]. Of these, the most prominent is Listeria monocytogenes, the species responsible for most cases of human listeriosis, an infection with a high mortality rate, at between $20 \%$ and $40 \%$ [2]. Listeriosis is more frequent and more serious in certain population segments termed at-risk groups, such as "YOPIs", the Young, the Old, the Pregnant, and the Immunocompromised, where the infection is linked to septicemia, meningitis, or miscarriages [3,4]. Nevertheless, it must be stressed that on occasion, for example after eating food with a high level of contamination, healthy adults have also been affected [5].

The incidence of human listeriosis worldwide ranges between 0.1 and 11.3 cases per million population per year [6]. Most cases of listeriosis are sporadic, and it is estimated that only $5 \%$ of cases of human illness are associated with outbreaks [7]. In the USA, approximately 1600 individuals contract listeriosis in its most severe forms each year (the incidence rate is around 0.26 per 100,000 population) and 260 of those affected die because of the infection [8]. Regarding the European Union, 2480 confirmed 
cases of invasive human listeriosis were reported in 2017 ( 0.48 cases per 100,000 population). The fatality rate was $13.8 \%$ (225 deaths among the 1633 confirmed cases with known outcomes), the highest among all food-borne diseases [9].

Listeria monocytogenes is a ubiquitous Gram-positive zoonotic bacterium displaying remarkable resistance to a variety of adverse environmental conditions. This microorganism tolerates high salinity (it can grow in the presence of $10 \% \mathrm{NaCl}$ ) [10] and strong acidity (it can withstand a $\mathrm{pH}$ range from 4.1 to 9.6) [11]. Moreover, it should be noted that it can cope with a wide range of temperatures and still grow (from $1{ }^{\circ} \mathrm{C}$ to $45^{\circ} \mathrm{C}$, although its optimum growth temperature is between $30{ }^{\circ} \mathrm{C}$ and $37^{\circ} \mathrm{C}$ ), and that it is a facultative anaerobe [10]. These characteristics encourage the appearance and persistence of L. monocytogenes in food-processing environments, where the bacterium can remain for long periods of time $[11,12]$.

Control of food-borne pathogenic bacteria requires an awareness of their sources and transmission routes [12]. For this, typing of strains is crucial. Serotyping is based on somatic $(\mathrm{O})$ and flagellar $(\mathrm{H})$ antigens. This technique is normally used to describe a microorganism, as well as in research into the ecological distribution, epidemiology and virulence of strains [13]. Thirteen serotypes have been identified for L. monocytogenes, comprising 1/2a, 1/2b, 1/2c, 3a, 3b, 3c, 4a, 4ab, 4b, 4c, 4d, 4e, and 7 [14], but only four of them $(1 / 2 a, 1 / 2 b, 1 / 2 c$ and $4 b)$ are responsible for the majority (approximately $95 \%$ ) of cases of human illness worldwide [15].

Presently, there is considerable concern for the increased prevalence of antibiotic-resistant bacteria, a problem of critical importance for public health around the world [16]. Although L. monocytogenes remains largely sensitive to clinically relevant antimicrobials, a climb in the prevalence of antibiotic-resistant strains has been observed in recent years, particularly in the case of isolates recovered from the food-chain $[17,18]$. One of the main measures for dealing with the problem of resistance to antibiotics is to have a program for monitoring resistant microorganisms, both in clinical environments and throughout the food-production chain [11,19]. This facilitates identification of trends in the generation of resistance to antibiotics and the planning of strategies for preventing their spread [11].

Biofilms are the predominant mode of microbial growth in nature [20]. They are defined as complex communities of microorganisms, embedded in an extracellular polymer matrix synthesized by the microorganisms themselves, with the ability to adhere to a variety of different biotic or abiotic surfaces [21]. As regards the food industry, once biofilms become established the resident bacteria display enhanced resistance to different environmental stresses, thus encouraging their persistence over long periods of time and increasing the risk of contamination of foodstuffs [22]. Biofilms present on equipment and installation surfaces in the food industry have been identified as the cause of the greater part of outbreaks of food-borne disease [23]. The ability to form biofilms differs from one L. monocytogenes strain to another, with major differences having been observed among the various serotypes [24].

The aim of this research work was to gain knowledge of the serotypes and susceptibility to antibiotics of a collection of L. monocytogenes isolates from red meat and poultry from North-West Spain, in order to assess the potential dangers posed by these strains for consumers. Additionally, microbial growth parameters and ability to form biofilm was compared for different Listeria species and serotypes.

\section{Materials and Methods}

\subsection{Strains}

A total of 118 strains of L. monocytogenes were used. These had previously been isolated from red meat (beef and pork) and poultry (chicken and turkey) samples in the Castile and León region (North-West Spain). One strain was selected for each positive sample. Strains were stored at $-80^{\circ} \mathrm{C}$ in tryptone soya broth (TSB, Oxoid Ltd. Hampshire, UK) with 20\% glycerol. 
Investigations of growth kinetics and the ability to form biofilm were undertaken with strains from the American Type Culture Collection (ATCC) and the Spanish Type Culture Collection (STCC): L. monocytogenes ATCC 19111 (serotype 1/2a), L. monocytogenes STCC 936 (serotype 1/2b), L. monocytogenes ATCC 19112 (serotype 1/2c), L. monocytogenes ATCC 19113 (serotype 3a), L. monocytogenes STCC 937 (serotype 3b), L. monocytogenes STCC 938 (serotype 3c), L. monocytogenes ATCC 19114 (serotype 4a), L. monocytogenes ATCC 13932 (serotype 4b), L. monocytogenes ATCC 19117 (serotype 4d), and L. ivanovii ATCC 19119.

Strains were inoculated into brain heart infusion (BHI, Oxoid) broth and incubated at $37^{\circ} \mathrm{C}$. After $24 \mathrm{~h}$ strains were streaked onto tryptone soy agar (TSA, Oxoid) plates, these being incubated at $37^{\circ} \mathrm{C}$ for $24 \mathrm{~h}$ and then stored at $4{ }^{\circ} \mathrm{C}$ while the experiments were performed.

\subsection{Serotyping}

Typing of the 118 strains of L. monocytogenes obtained from red meat and poultry was carried out by the agglutination method with the Seiken Listeria antisera set (Denka Seiken Co., Tokyo, Japan), in accordance with the manufacturer's instructions. Twelve antisera were used, eight for determining somatic (O) antigens: I/II, I, IV, V/VI, VI, VII, VIII, and IX, and four for determining flagellar (H) antigens: A, B, C, and D. Strains were grouped into lineages on the basis of their serotype: lineage I, comprising serotypes $1 / 2 b, 3 b, 3 c$, and $4 b$, lineage II with serotypes $1 / 2 a, 1 / 2 c$ and $3 a$, and lineages III and IV, comprising serotypes $4 \mathrm{a}$ and $4 \mathrm{c}[25,26]$.

\subsection{Antibiotic Susceptibility Testing}

A total of 72 L. monocytogenes strains obtained from red meat and poultry were screened for susceptibility to a panel of 26 antimicrobial drugs on Mueller-Hinton agar (Oxoid) by a disc diffusion method. Strains were selected in an attempt to ensure the greatest possible diversity regarding serotypes. The following discs were used: amikacin (AK; $30 \mu \mathrm{g})$, streptomycin (STR; $10 \mu \mathrm{g})$, gentamycin (CN; $30 \mu \mathrm{g})$, kanamycin $(\mathrm{K} ; 30 \mu \mathrm{g})$, tobramycin (TOB; $10 \mu \mathrm{g})$, rifampicin (RD; $5 \mu \mathrm{g})$, imipenem (IPM; $10 \mu \mathrm{g}$ ), cephalothin (KF; $30 \mu \mathrm{g})$, cefazolin (KZ; $30 \mu \mathrm{g}$ ), cefoxitin (FOX; $30 \mu \mathrm{g}$ ), cefotaxime (CTX; $30 \mu \mathrm{g})$, cefepime (FEP; $30 \mu \mathrm{g}$ ), chloramphenicol (C; $30 \mu \mathrm{g}$ ), enrofloxacin (ENR; $5 \mu \mathrm{g}$ ), ciprofloxacin (CIP; $5 \mu \mathrm{g}$ ), nalidixic acid (NA; $30 \mu \mathrm{g}$ ), vancomycin (VA; $30 \mu \mathrm{g}$ ), amoxicillin-clavulanic acid (AMC; $30 \mu \mathrm{g}$ ), sulbactam-ampicillin (SAM; $20 \mu \mathrm{g}$ ), trimethoprim-sulfamethoxazole (SXT; $25 \mu \mathrm{g}$ ), erythromycin (E; $15 \mu \mathrm{g})$, nitrofurantoin (F; $300 \mu \mathrm{g})$, ampicillin (AMP; $10 \mu \mathrm{g}$ ), oxacillin (OX; $1 \mu \mathrm{g})$, penicillin (P; $10 \mu \mathrm{g})$, and tetracycline $(\mathrm{TE} ; 30 \mu \mathrm{g})$. All the antibiotic discs were obtained from Oxoid. After incubation at $37^{\circ} \mathrm{C}$ for $18-24 \mathrm{~h}$, inhibition zones were measured and scored as sensitive, intermediate (reduced susceptibility) or resistant according to the Clinical and Laboratory Standards Institute (CLSI, Wayne, PA, USA) guidelines [27]. Staphylococcus aureus ATCC 29213 and Escherichia coli ATCC 25922 were used as reference strains for antibiotic disc control.

\subsection{Growth Kinetics}

For growth curve studies, nine L. monocytogenes strains, each of a different serotype, were used, together with one L. ivanovii strain. Before use, strains were transferred to TSB and incubated for five hours at $37^{\circ} \mathrm{C}$. These bacterial cultures contained approximately $10^{8} \mathrm{cfu} / \mathrm{mL}$. Three decimal dilutions were performed in TSB. The wells of 100-well polystyrene microtiter plates (Oy Growth Curves Ab Ltd., Helsinki, Finland) were filled with $25 \mu \mathrm{L}$ of the third dilution of this bacterial culture and $225 \mu \mathrm{L}$ of TSB to attain a concentration of $10^{4} \mathrm{cfu} / \mathrm{mL}$ in the well. Bacterial growth at $37^{\circ} \mathrm{C}$ was monitored before incubation (at hour 0 ) and every hour thereafter until $48 \mathrm{~h}$ had elapsed. Growth was determined by measuring the optical density (OD) at $420 \mathrm{~nm}$ to $580 \mathrm{~nm}\left(\mathrm{OD}_{420-580}\right)$ using a Bioscreen C MBR device (Oy Growth Curves $\mathrm{Ab}$ ). The micro-well plates were agitated for one minute prior to the measurement of turbidity. The model used to fit growth curves to the data obtained was the modified Gompertz equation [28]: ODt $=\mathrm{A}+\mathrm{B} \times \exp (-\exp (2.71828183 \times \mu \times(\mathrm{L}-\mathrm{t}) / \mathrm{B}+1))$, where $\mathrm{t}$ is the time in hours that has elapsed since inoculation, ODt is optical density (determined at $420 \mathrm{~nm}$ to $580 \mathrm{~nm}$ ) 
at time $t, L$ is the time when the lag period ends (hours), $\mu$ is the maximum growth rate achieved $\left(\triangle \mathrm{OD}_{420-580} / \mathrm{h}\right), \mathrm{B}$ is the increase in $\mathrm{OD}_{420-580}$ from inoculation to the stationary phase $(\mathrm{E})$, and $\mathrm{A}$ is the upper asymptote curve $\left(\mathrm{OD}_{420-580}\right.$ in the stationary stage, $\left.\mathrm{E}\right)$ minus $\mathrm{B}$. The time to stationary phase ( $\mathrm{T}$; hours) was calculated as the time required to reach a concentration equal to, or higher than, $99 \%$ of the value for $\mathrm{E}$ [20]. Values for $\mathrm{L}, \mu, \mathrm{E}$ and $\mathrm{T}$ were obtained for each strain and replication by fitting a sigmoidal curve to the data set using a Marquardt algorithm that calculates those parameter values which give the minimum residual sum of squares. Goodness of fit was evaluated using the coefficient of determination $\left(R^{2}\right)$. All experiments were replicated three times on separate days. Each day the experiments were performed in duplicate.

\subsection{Biofilm Determination}

For investigating the production of biofilm, the same strains were used as for the growth curves. Formation of biofilms was determined by measuring optical density at $580 \mathrm{~nm}\left(\mathrm{OD}_{580}\right)$ of cells adhering to a microtiter plate (Oy Growth Curves $\mathrm{Ab}$ ) [20]. Each strain was assessed in triplicate and the procedure was repeated on two separate days. Strains were first incubated in TSB for five hours at $37^{\circ} \mathrm{C}$, until a cell concentration of approximately $10^{8} \mathrm{cfu}$ was attained. Wells were filled with $25 \mu \mathrm{L}$ of the third dilution of this bacterial culture and $225 \mu \mathrm{L}$ of TSB to obtain a concentration of $10^{4} \mathrm{cfu} / \mathrm{mL}$. The negative controls (ten in each plate) contained $250 \mu \mathrm{L}$ of TSB only. The plates were incubated aerobically for $24 \mathrm{~h}$ at $37^{\circ} \mathrm{C}$. The contents of the plate were then poured off and the wells washed once with $300 \mu \mathrm{L}$ of distilled water. The remaining attached bacteria were fixed by adding $250 \mu \mathrm{L}$ of methanol and letting stand for $15 \mathrm{~min}$ at room temperature. The plates were then emptied, air-dried and stained with $250 \mu \mathrm{L}$ per well of crystal violet (solution at $0.5 \%$ in sterile distilled water), letting this stand for five minutes. Excess stain was rinsed off by placing the micro-well plate under running tap water. The plates were air-dried and then the dye bound to the adherent cells was re-solubilized with $250 \mu \mathrm{L}$ of $33 \%(v / v)$ acetic acid per well, the substance being allowed to work for one minute. Finally, the optical density $\left(\mathrm{OD}_{580}\right)$ was measured in each well using a Bioscreen C MBR (Oy Growth Curves $\mathrm{Ab}$ ), plates being shaken for one minute before reading. All experiments were replicated three times on separate days. Each day the experiments were performed in duplicate.

The cut-off $\mathrm{OD}(\mathrm{ODc})$ was defined as three standard deviations above the mean $\mathrm{OD}_{580}$ of the negative controls. Strains were classified into four categories: non-biofilm producers, when OD $\leq$ ODc, weak biofilm producers, when ODc $<\mathrm{OD} \leq(2 \times \mathrm{ODc})$, moderate biofilm producers, when $(2 \times \mathrm{ODc})<$ $\mathrm{OD} \leq(4 \times \mathrm{ODc})$, or strong biofilm producers, when $(4 \times \mathrm{ODc})<\mathrm{OD}$.

\subsection{Statistical Analysis}

The values obtained for each growth parameter $(\mathrm{L}, \mu, \mathrm{E}$ and $\mathrm{T})$ and the $\mathrm{OD}_{580}$ (crystal violet assay) were compared for statistical significance using analysis of variance techniques. Mean separations were obtained using Duncan's multiple range test. Significance was determined at the $5 \%(p<0.05)$ level. The Statistica ${ }^{\circledR} 8.0$ package (Statsoft Ltd., Tulsa, OK, USA) was used for calculations.

\section{Results and Discussion}

\subsection{Serotyping}

With respect to somatic $(\mathrm{O})$ antigens, agglutination was observed with one or more of the eight antisera in $103(87.3 \%)$ out of the 118 strains studied (Figure 1). No agglutination reactions took place in 15 strains $(12.7 \%)$, which could not be serotyped. Other researchers also observed strains of L. monocytogenes that could not be typed by agglutination techniques [29]. Furthermore, the methods used did not permit distinction of serotype $4 \mathrm{e}$ from $4 \mathrm{~b}$ and $4 \mathrm{~d}$, since these strains presented agglutination reactions with the same sera.

Regarding flagellar $(\mathrm{H})$ antigens, no agglutination reactions were observed in any instance. The impossibility of detecting $\mathrm{H}$ antigens has also been noted by other authors [30-34]. Antisera for 
determining flagellar antigens react with the protein flagellin, this being found in the flagella produced by L. monocytogenes. The reason there was no agglutination in this work may be that the strains tested presented low or null motility at $25^{\circ} \mathrm{C}$ in the culture medium used, BHI with $0.2 \%$ agar [33], or that L. monocytogenes formed little flagellin [32], or that the weakness of the antigen-antibody reactions makes agglutination barely noticeable [34]. To improve L. monocytogenes typing, a multiplex polymerase chain reaction (PCR) assay that separates serotypes into distinct PCR serogroups have been developed [35].

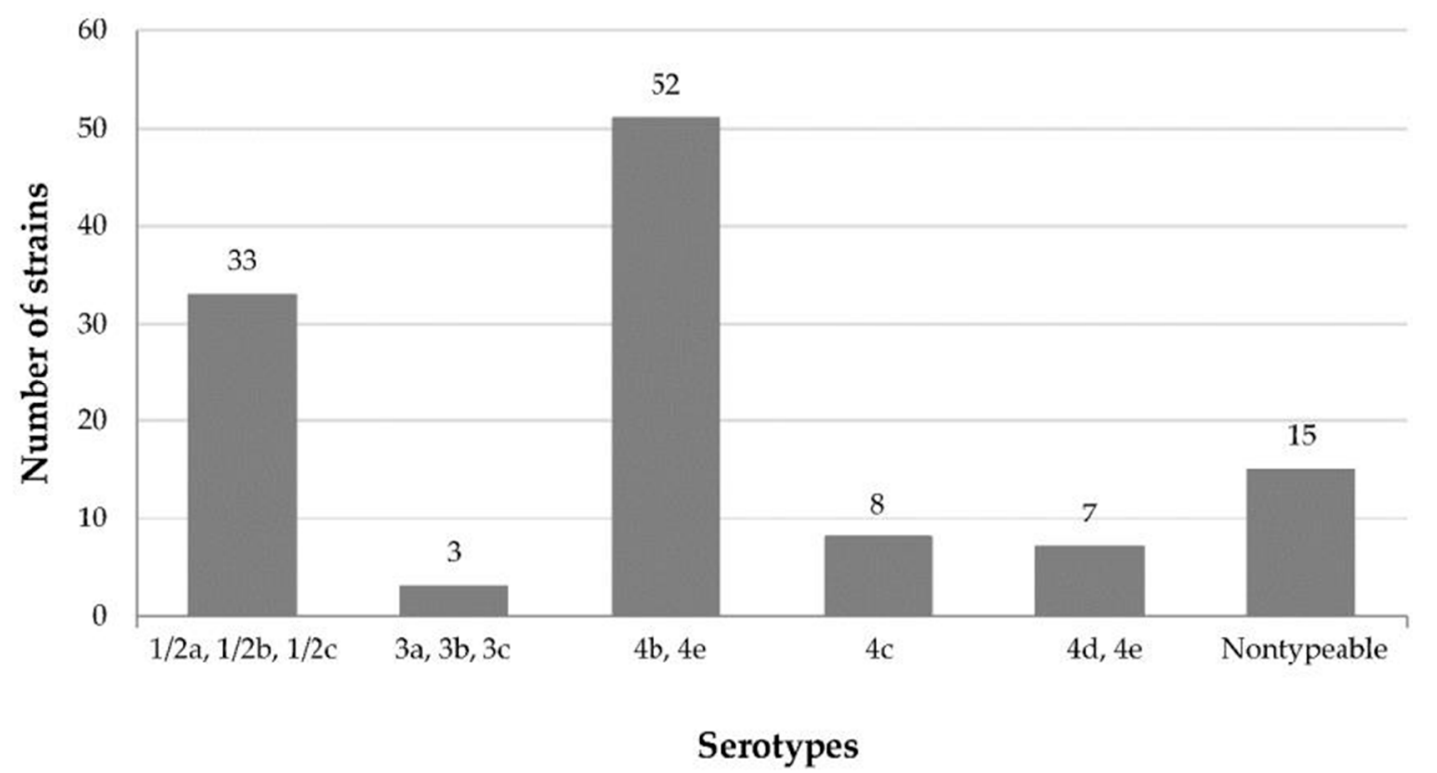

Figure 1. Serotyping for 118 L. monocytogenes isolates from red meat and poultry in Spain.

Flagellar $(\mathrm{H})$ antigens permit a distinction between serotypes $1 / 2 \mathrm{a}, 1 / 2 \mathrm{~b}$ and $1 / 2 \mathrm{c}$, and also between $3 a, 3 b$, and 3c. Due to the absence of agglutination reactions for the isolates tested here, separation of these strains by serotype was not possible; therefore, these were assigned collectively to Group $1 / 2$ (serotypes $1 / 2 a, 1 / 2 b$ and $1 / 2 c$ ) or Group 3 (serotypes $3 a, 3 b$, and $3 c$ ). Taking this into account, serotyping results are shown in Figure 1, with most strains (82.5\% of those typed) being assigned to Groups $1 / 2$ and $4 b / 4 e$. These results are worrying, because serotypes $1 / 2 a, 1 / 2 b, 1 / 2 c$ and $4 b$ are those most often involved in human listeriosis [26]. Strains of Group $1 / 2$ been associated with sporadic cases of listeriosis in Europe and North America, while serotype $4 \mathrm{~b}$ is responsible for most of the outbreaks of disease $[6,36,37]$.

Strains in Group 1/2, to which $32.0 \%$ of the isolates typed were assigned, have often been detected in food, including meat products [12,15,38-42]. Serotype 1/2a is the most prevalent in food-processing environments; thereby indicating its robust ecological adaptability [39]. This serotype appears to contain more plasmids than other serotypes. Since plasmids frequently carry genes that confer resistance to antimicrobial agents, including sanitizers used in processing operations, bacteria harboring such plasmids would have a considerable advantage in these environments [25].

Just $2.9 \%$ of strains typed belonged to Group 3. This low percentage agrees with the findings of other researchers, who observed a low prevalence of strains of serotypes $3 a, 3 b$, and $3 c$ both in foodstuffs [15] and among isolates of clinical origin [27,31,38].

Although no strains of serotype 4a were found, several isolates were determined to be of serotypes $4 \mathrm{~b} / 4 \mathrm{e}, 4 \mathrm{c}$ and $4 \mathrm{~d} / 4 \mathrm{e}$. In fact, the $4 \mathrm{~b} / 4 \mathrm{e}$ Group accounted for $50.5 \%$ of isolates that were successfully typed. This percentage is similar to those noted specifically for L. monocytogenes serotype $4 \mathrm{~b}$ in meat products by Meloni et al. [43] in Italy, Vasilev et al. [44] in Israel, Martins and Germano [45] in Brazil and Fallah et al. [46] in Iran. These authors observed that 50\%, 45\%, 38\% and $45 \%$, respectively, of isolates from foodstuffs belonged to serotype $4 \mathrm{~b}$. It should be pointed out that this serotype, besides being the type 
most often implicated in outbreaks of human listeriosis, appears to have greater potential for virulence than others. Therefore, this serotype is detected more often in patients who have suffered meningitis than in those not having shown any infection in their blood [15]. It should be noted that an important outbreak of listeriosis that occurred in Spain during August and September 2019 by a chilled roasted pork meat product has been linked to L. monocytogenes serotype $4 \mathrm{~b}[47,48]$.

Of all strains that could be serotyped here, $7.8 \%$ belonged to serotype $4 \mathrm{c}$. Other studies examining L. monocytogenes from meat samples have also reported the presence of this serotype [36,38,42-44]. It must be pointed out that strains of serotype $4 \mathrm{c}$ are associated with animals and are not normally isolated in cases of human listeriosis [36]. The remaining serotype 7 isolates (6.8\%) typed here were assigned to the $4 \mathrm{~d} / 4 \mathrm{e}$ Group. Other researchers have reported the prevalence of these serotypes to be low or absent from foodstuffs $[38,40,45,46]$. Moreover, these serotypes have not been associated with any cases of human listeriosis $[31,39]$.

\subsection{Antibiotic Resistance}

The susceptibility of 72 strains of L. monocytogenes obtained from red meat and poultry samples was tested against 26 antibiotics, the results for which are presented in Figure 2. Overall most strains were found to be susceptible to most antibiotics tested. However, for six of the antibiotics there was a high prevalence of resistance among L. monocytogenes isolates. These were: cefoxitin $(77.8 \%$ of strains resistant), cefotaxime $(62.5 \%)$, cefepime $(73.6 \%)$, nalidixic acid $(97.2 \%)$, nitrofurantoin $(51.4 \%)$ and oxacillin (93.1\%). Resistance to one or more of these antibiotics among Listeria spp. has been reported by other researchers $[17,19,49-53]$. While the abovementioned antibiotics are used for treating several infections in humans [54] and animals [55], they are not used in listeriosis therapy, where $\beta$-lactams are the antibiotics of first choice, normally ampicillin, administered alone or in combination with gentamicin. In cases of allergy to $\beta$-lactams, possible alternatives include erythromycin, vancomycin, trimethoprim/sulfamethoxazole, and fluoroquinolones [17]. Rifampicin, tetracycline and chloramphenicol are also used to treat listeriosis [56]. It should be stressed that several strains showed some resistance to amikacin ( $2.8 \%$ of strains), streptomycin (1.4\%), gentamycin $(1.4 \%)$, rifampicin $(1.4 \%)$, enrofloxacin $(1.4 \%)$, ciprofloxacin $(2.8 \%)$, amoxicillin-clavulanic acid $(1.4 \%)$, ampicillin $(2.8 \%)$ and penicillin $(9.7 \%)$.

In L. monocytogenes two MFS (Major Facilitator Superfamily) efflux pumps, MdrL and Lde, have been described to contribute to antibiotic resistance. Lde can confer resistance to hydrophilic fluoroquinolones. Also, within L. monocytogenes, MdrL has been described as responsible for benzalkonium resistance when overexpressed [56] and it is able to extrude macrolides, cefotaxime and heavy metals as well $[57,58]$.

Many strains of L. monocytogenes show natural resistance to cephalosporins, especially third and fourth generation $[19,53]$. This fact is borne out by the results of the present research work, in which resistance was noted to cephalosporins, whether second (cefoxitin), third (cefotaxime) or fourth (cefepime) generation. Resistance to nitrofurantoin may be due to the excessive use of this compound in veterinary medicine some years ago [53]. Although today it is a banned substance because of its toxicological risks for consumers, mechanisms for cross-resistance or co-resistance may be related to the presence of resistance to this antimicrobial [16]. The intrinsic resistance of Listeria spp. to nalidixic acid was noted some time ago, and in fact this antibiotic is habitually used in selective media for isolating these microorganisms [51,59]. In the present study no strain presented any susceptibility to this antibiotic.

Although L. monocytogenes is generally susceptible to a broad range of antibiotics, the emergence of resistant strains observed in recent years is perplexing [46]. Among other causes, this enhancement of resistance may be due to progressive acquisition of antibiotic resistance genes from other bacterial genera through horizontal transmission of mobile genetic elements, such as plasmids or transposons [18]. 


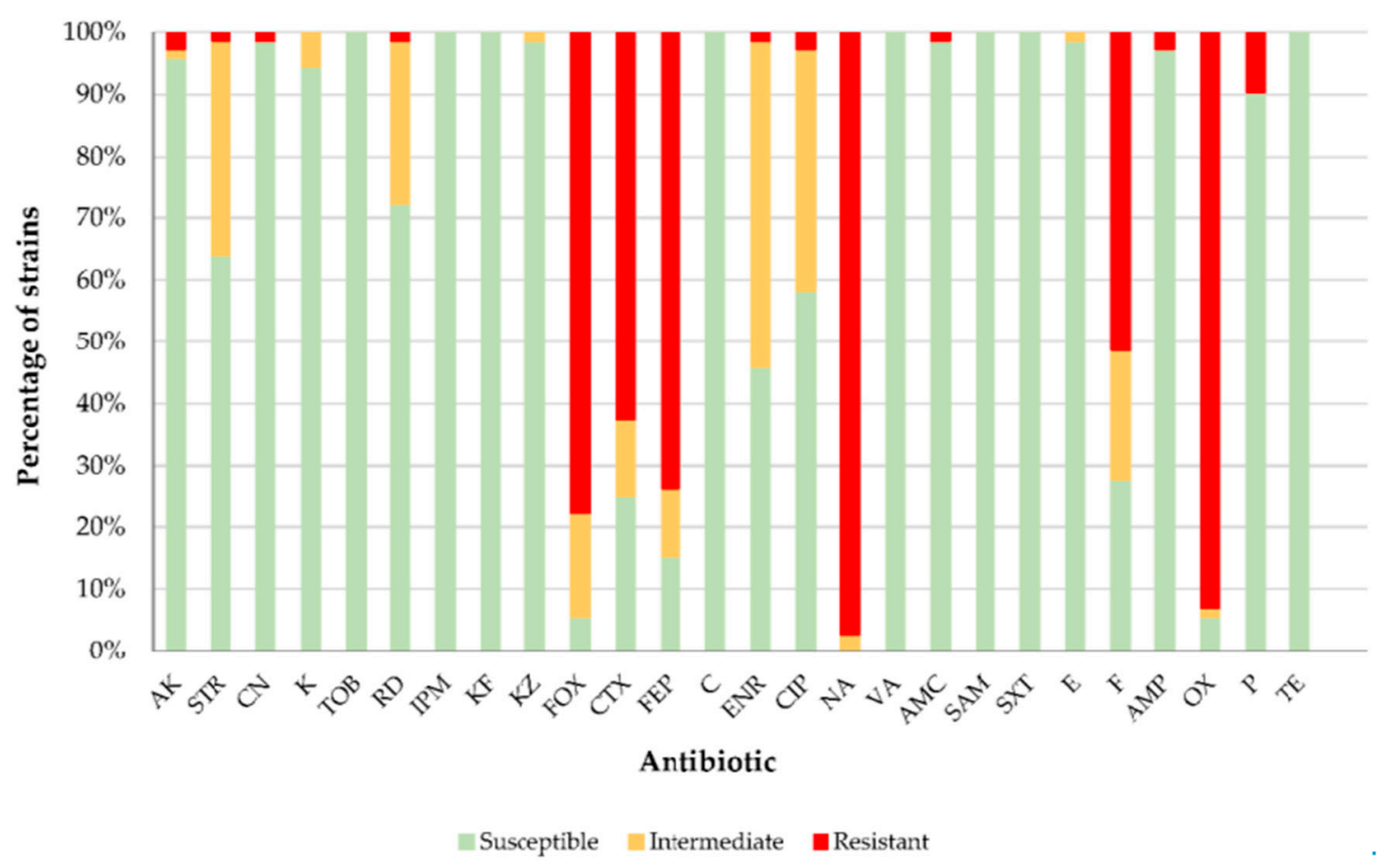

Figure 2. Percentage of L. monocytogenes isolates $(n=72)$ from red meat and poultry susceptible $(\mathrm{S})$, intermediate (with reduced susceptibility; I) and resistant (R) to antibiotics. Amikacin (AK), streptomycin (STR), gentamycin $(\mathrm{CN})$, kanamycin $(\mathrm{K})$, tobramycin (TOB), rifampicin (RD), imipenem (IPM), cephalothin (KF), cefazolin (KZ), cefoxitin (FOX), cefotaxime (CTX), cefepime (FEP), chloramphenicol (C), enrofloxacin (ENR), ciprofloxacin (CIP), nalidixic acid (NA), vancomycin (VA), amoxicillin-clavulanic acid (AMC), sulbactam-ampicillin (SAM), trimethoprim-sulfamethoxazole (SXT), erythromycin (E), nitrofurantoin (F), ampicillin (AMP), oxacillin (OX), penicillin (P), tetracycline (TE).

\subsection{Growth Kinetics}

Figure 3 shows the growth curves for nine strains of L. monocytogenes of various serotypes and one strain of L. ivanovii. Table 1 gives the growth parameters for these strains based on the modified Gompertz model. As in other works [60-62], the present research revealed great variability among the growth parameters of the different strains of Listeria spp. tested. The lag phase (L) reflects the time needed for cells to adapt to a new substrate and begin to multiply [63]. Listeria monocytogenes strains of serotypes $3 a(a t 6.597 \pm 0.418 \mathrm{~h}), 3 \mathrm{~b}(5.717 \pm 0.086 \mathrm{~h}), 4 \mathrm{~b}(5.739 \pm 0.111 \mathrm{~h})$ and $4 \mathrm{~d}(5.729 \pm 0.133 \mathrm{~h})$ showed a trend to have the longest values for $\mathrm{L}(p<0.05)$. In contrast, the L. monocytogenes isolate of serotype $1 / 2 b$ had the shortest duration for $L$, at $1.839 \pm 2.998 \mathrm{~h}(p<0.05)$. These findings are similar to those of Vialette et al. [64], who observed that the duration of the lag phases of L. monocytogenes of serotypes $1 / 2 \mathrm{~b}(0.9 \pm 0.2 \mathrm{~h})$ and $4 \mathrm{~b}(1.4 \pm 0.1 \mathrm{~h})$ were the shortest and longest, respectively, among a set of strains of L. monocytogenes as they grew at $20^{\circ} \mathrm{C}$. In another research work, Sant'Ana et al. [65] noted that the average value for $\mathrm{L}$ in strains of serotype $4 \mathrm{~b}$ incubated at $30^{\circ} \mathrm{C}$ was $2.4 \pm 0.8 \mathrm{~h}$, approximately half that of the strain of that serotype trialed in the current research.

The average $L$ value for the nine strains of L. monocytogenes in the current investigation was $4.672 \pm 0.971 \mathrm{~h}$. This figure is higher than that observed by Xuan et al. [66], who indicated that the average lag phase at $30^{\circ} \mathrm{C}$ was $3.339 \pm 0.173 \mathrm{~h}$. It should be noted, however, that the abovementioned authors tested a single strain (ATCC 19114; serotype 4a). The differences in duration of L seen in the various research consulted may be linked to the varying nutrition requirements of the strains [67]. Variations between reports could be also attributed to the different methods applied or the different curve-fitting models used [68].

The strains with greatest growth rates belonged to serotypes $3 b(0.387 \pm 0.016 \Delta \mathrm{OD} / \mathrm{h})$, $4 \mathrm{~b}(0.396 \pm 0.026 \Delta \mathrm{OD} / \mathrm{h})$ and $4 \mathrm{~d}(0.345 \pm 0.066 \Delta \mathrm{OD} / \mathrm{h})$. Strains of L. monocytogenes serotypes $1 / 2 \mathrm{a}$ 
and $1 / 2 b$ showed a trend to have the slowest rates of growth $(0.073 \pm 0.018$ and $0.088 \pm 0.049 \Delta \mathrm{OD} / \mathrm{h}$, respectively). These results coincide with the findings of Pan et al. [24], who observed a higher growth rate in strains of serotype $4 \mathrm{~b}$ than in those of serotype $1 / 2 \mathrm{a}$. These are worrying findings taking into account that strains of serotype $4 \mathrm{~b}$ are frequently associated with outbreaks of human listeriosis. In work by Sant'Ana et al. [65], the average growth rate of strains of serotype $4 \mathrm{~b}$ incubated at $30^{\circ} \mathrm{C}$ was $0.22 \pm 0.02 \Delta \mathrm{OD} / \mathrm{h}$, lower figures than in the current investigation. In the work being reported here the average growth rate observed for strains of L. monocytogenes $(0.202 \pm 0.042 \Delta \mathrm{OD} / \mathrm{h})$ was lower $(p<0.05)$ than for L. ivanovii $(0.272 \pm 0.019 \Delta \mathrm{OD} / \mathrm{h})$.
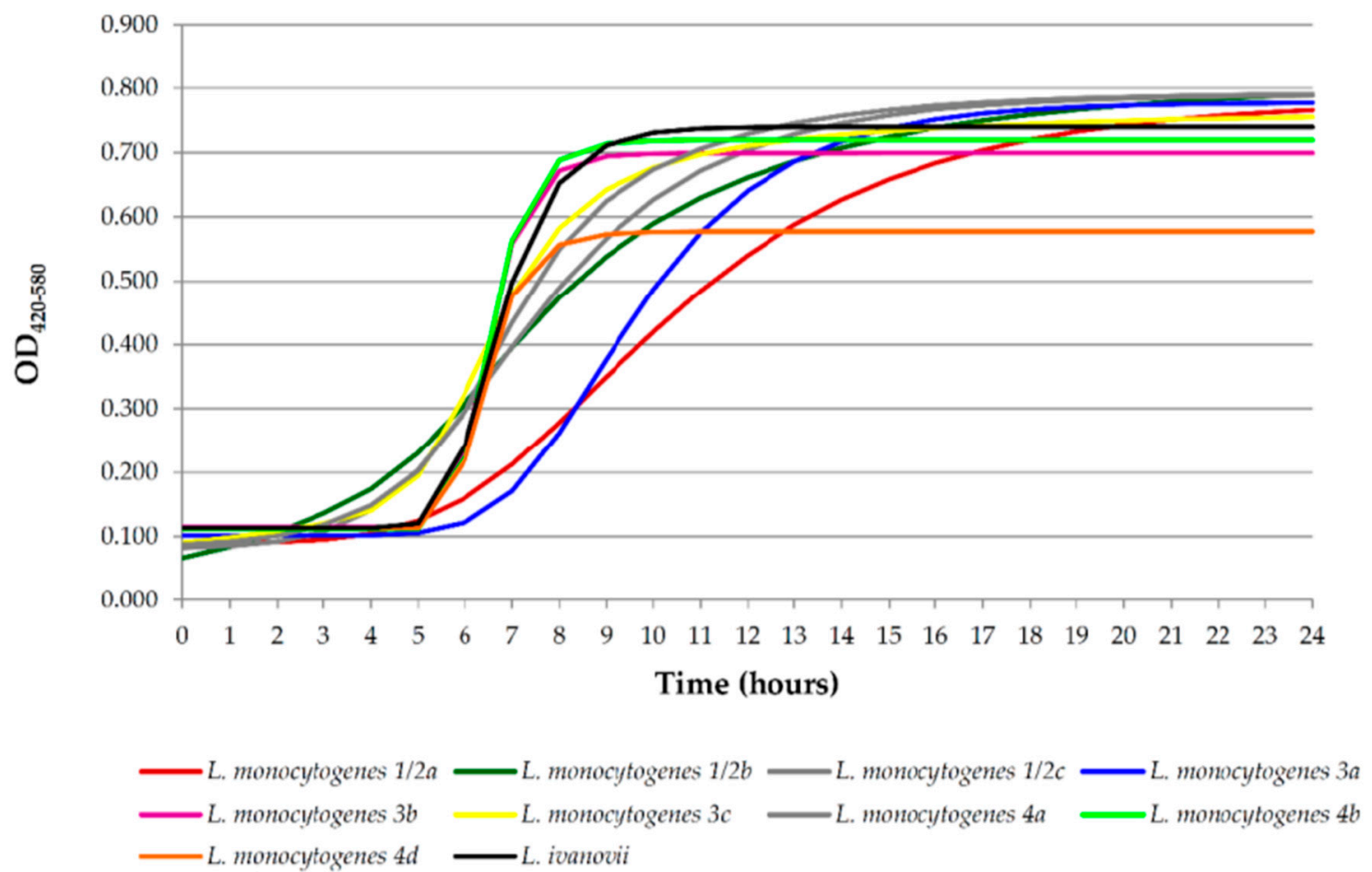

Figure 3. Growth curves (optical density at 420-580 nm) in tryptone soya broth for Listeria ivanovii and various serotypes of Listeria monocytogenes incubated for $24 \mathrm{~h}$ at $37^{\circ} \mathrm{C}$.

Table 1. Microbial growth parameters recorded for ten strains of Listeria spp. incubated in tryptone soy broth for $24 \mathrm{~h}$ at $37^{\circ} \mathrm{C}$.

\begin{tabular}{ccccc}
\hline \multirow{2}{*}{ Strain } & \multicolumn{4}{c}{ Growth Kinetic Parameters } \\
\cline { 2 - 5 } & $\mathbf{L}$ & $\mu$ & $\mathbf{E}$ & $\mathbf{T}$ \\
\hline Listeria monocytogenes 1/2a & $5.319 \pm 0.504^{\mathrm{cde}}$ & $0.073 \pm 0.018^{\mathrm{a}}$ & $0.781 \pm 0.015^{\mathrm{de}}$ & $19.800 \pm 0.447^{\mathrm{d}}$ \\
Listeria monocytogenes 1/2b & $1.839 \pm 2.998^{\mathrm{a}}$ & $0.088 \pm 0.049^{\mathrm{ab}}$ & $0.805 \pm 0.031^{\mathrm{e}}$ & $18.000 \pm 2.646^{\mathrm{cd}}$ \\
Listeria monocytogenes 1/2c & $3.765 \pm 0.957^{\mathrm{bc}}$ & $0.103 \pm 0.030^{\mathrm{abc}}$ & $0.790 \pm 0.038^{\mathrm{e}}$ & $17.600 \pm 2.074^{\mathrm{cd}}$ \\
Listeria monocytogenes 3a & $6.597 \pm 0.418^{\mathrm{e}}$ & $0.118 \pm 0.022^{\mathrm{abc}}$ & $0.778 \pm 0.024^{\mathrm{de}}$ & $17.800 \pm 1.304^{\mathrm{cd}}$ \\
Listeria monocytogenes 3b & $5.717 \pm 0.086^{\mathrm{e}}$ & $0.387 \pm 0.016^{\mathrm{e}}$ & $0.699 \pm 0.053^{\mathrm{b}}$ & $9.167 \pm 0.408^{\mathrm{a}}$ \\
Listeria monocytogenes 3c & $3.479 \pm 2.846^{\mathrm{b}}$ & $0.164 \pm 0.078^{\mathrm{c}}$ & $0.761 \pm 0.024^{\mathrm{cde}}$ & $14.000 \pm 3.674^{\mathrm{b}}$ \\
Listeria monocytogenes 4a $^{\mathrm{b}}$ & $3.864 \pm 1.656^{\mathrm{bcd}}$ & $0.144 \pm 0.081^{\mathrm{bc}}$ & $0.793 \pm 0.037^{\mathrm{e}}$ & $15.600 \pm 3.435^{\mathrm{bc}}$ \\
Listeria monocytogenes 4b & $5.739 \pm 0.111^{\mathrm{e}}$ & $0.396 \pm 0.026^{\mathrm{e}}$ & $0.719 \pm 0.033^{\mathrm{bc}}$ & $9.167 \pm 0.408^{\mathrm{a}}$ \\
Listeria monocytogenes 4d & $5.729 \pm 0.133^{\mathrm{e}}$ & $0.345 \pm 0.066^{\mathrm{e}}$ & $0.578 \pm 0.049^{\mathrm{a}}$ & $9.000 \pm 0.894^{\mathrm{a}}$ \\
Listeria ivanovii & $5.528 \pm 0.226^{\mathrm{de}}$ & $0.272 \pm 0.019^{\mathrm{d}}$ & $0.740 \pm 0.023^{\mathrm{bcd}}$ & $11.000 \pm 0.000^{\mathrm{a}}$ \\
\hline
\end{tabular}

$\mathrm{L}$, lag phase (h); $\mu$, maximum growth rate $(\Delta \mathrm{DO} / \mathrm{h}) ; \mathrm{E}$, maximum optical density (OD; determined at $420-580 \mathrm{~nm})$; $\mathrm{T}$, time (h) elapsed to stationary phase. Each value is the mean of six determinations. Average values in the same column without any letter in common are significantly different $(p<0.05)$.

Maximum $\mathrm{OD}_{420-580}$ at stationary phase (E) reached by the strains of Listeria spp. was an average of $0.738 \pm 0.074$, lower than noted by other authors consulted. Thus, Mytilinaios et al. [69] observed 
that maximum $\mathrm{OD}_{600}$ was 0.99 when strains were incubated in TSB at $37^{\circ} \mathrm{C}$, and Augustin et al. [60] found an $\mathrm{OD}_{600}$ of $0.97 \pm 0.06$ when strains were incubated at $14.5^{\circ} \mathrm{C}$ in tryptone soya yeast extract (TSYE). In the investigation presented here, the highest maximum $\mathrm{OD}_{420-580}$ was attained by the strain L. monocytogenes serotype $1 / 2 b(0.805 \pm 0.031)$, which also presented the shortest lag phase. This fact suggests that there is an inverse relationship between the length of the lag phase and the maximum growth achieved by the bacterial population. Furthermore, it was also observed that other serotypes with a long lag phase $(1 / 2 a, 3 a, 3 b, 4 b$, or $4 d$ ) attained a relatively limited $E$ (Figure 3 ). Aguirre and Koutsoumanis [70] had similar findings using a method based on colony forming units counts. These authors observed that the longer the lag phase lasted, the smaller was the population size reached. It must be pointed out that the dimensions of cells may vary between strains and thus cause the differences in OD values observed. Further studies are needed to clarify the reasons for these differences among strains as regards their maximum OD.

The time elapsed before the stationary phase was reached $(\mathrm{T})$ was quite variable between strains, the average values being approximately $14 \mathrm{~h}$. The L. monocytogenes $3 \mathrm{~b}, 4 \mathrm{~b}$ and $4 \mathrm{~d}$ strains took less time (approximately nine hours) than the remaining strains to reach this phase $(p<0.05)$. The strains presenting the highest values for $T$ were those belonging to serotypes 1/2a (approximately $20 \mathrm{~h}$ ), 1/2b, $1 / 2 \mathrm{c}$ and $3 \mathrm{a}$ (approximately $18 \mathrm{~h}$ ) and $4 \mathrm{a}$ (nearly $16 \mathrm{~h}$ ). The L. invanovii strain took $11 \mathrm{~h}$ to reach stationary phase. Initial inoculum levels will influence lag periods and consequently time to stationary phase. Mytilinaios et al. [69] observed that when the inoculum was $5 \log$ units, the time needed to reach the stationary phase when incubated in TSB at $37^{\circ} \mathrm{C}$ was $12 \mathrm{~h}$. In contrast, when the starting concentration was $3.3 \log _{10} \mathrm{cfu} / \mathrm{mL}$, this value was $16 \mathrm{~h}$. On the basis of the study cited, keeping in mind that the initial concentration of inoculum in the current investigation was approximately 4 log units, it was to be expected that $\mathrm{T}$ would be around $14 \mathrm{~h}$, a time corresponding well with the average recorded.

\subsection{Biofilm Formation}

In agreement with other studies [21,71,72] all Listeria strains examined here were able to form biofilm under the experimental conditions tested (Figure 4). The mean $\mathrm{OD}_{580}$ (crystal violet assay) value for the 10 Listeria spp. strains was $0.89 \pm 0.13$. Even though comparison between reports must be performed with caution because the different methodologies used, our results were similar to the $\mathrm{OD}_{580}$ measurements of 0.8 reported by Kadam et al. [73], who examined biofilm formation for $143 \mathrm{~L}$. monocytogenes strains after incubation at $37^{\circ} \mathrm{C}$ for $24 \mathrm{~h}$ in TSB. The average $\mathrm{OD}_{580}$ found in the present study fit in the wide range of values observed by Nilsson et al. [74] for a collection of $95 \mathrm{~L}$. monocytogenes strains incubated at $37^{\circ} \mathrm{C}$ for $24 \mathrm{~h}$, where $\mathrm{OD}_{595}$ values ranged from 0.02 to 1.68. These authors used BHI, which is more nutritious than TSB. It should be noted that the ability to form biofilm may vary as a function of availability of nutrients [74].

L. monocytogenes strains of serotypes 3a and $4 \mathrm{a}$, and L. ivanovii were strong producers of biofilm, with significant differences $(p<0.05)$ relative to the remaining strains. The $\mathrm{OD}_{580}$ observed for L. ivanovii in the present investigation was $1.81 \pm 0.29$, a value similar to that obtained by Nyenje et al. [75], where $\mathrm{OD}_{595}$ was $1.754 \pm 0.763$. There is little information available regarding the biofilm-forming capacity of L. ivanovii. This is most likely because this bacterium appears to have low virulence potential in humans as demonstrated by the few cases of human listeriosis reported. It should be noted that in the present study the $\mathrm{OD}_{580}$ for L. monocytogenes $(0.79 \pm 0.82$; average figure for all the strains trialed) was lower $(p<0.01)$ than the $\mathrm{OD}_{580}$ for L. ivanovii $(1.81 \pm 0.29)$.

Listeria monocytogenes strains of the serotypes $1 / 2 a, 1 / 2 b$ and $1 / 2$ c gave rise to the formation of moderate amounts of biofilm, while the strain of serotype $4 \mathrm{~b}$ was a weak biofilm producer; albeit it should be noted that the observed differences between values were not significant $(p>0.05)$. The greater production of biofilm by isolates of Group $1 / 2$ relative to serotype $4 \mathrm{~b}$ is a finding in agreement with the results of other authors $[24,73,74]$. Strains $3 b, 3 c, 4 b$, and $4 d$ showed only weak production of biofilm. The fact that the serotype most frequently involved in outbreaks of human listeriosis (4b) has a weak ability to form biofilms is a favorable finding in the food safety scenario. 
Based on subtyping techniques, L. monocytogenes can be classified into large genetic groups with differing characteristics, termed lineages [76]. Most cases of human listeriosis are associated with lineages I and II [25,76-78]. Specifically, cases forming part of outbreaks are related to lineage I, while sporadic cases are linked to lineage II [77]. It should be pointed out that strains of serotypes $3 \mathrm{~b}, 3 \mathrm{c}$, and $4 \mathrm{~b}$, which showed the least capacity for biofilm production, belong to lineage $\mathrm{I}$, which is characterized by having very slight genetic diversity $[25,76,78]$. Lineage II is made up of serotypes $1 / 2 \mathrm{a}, 1 / 2 \mathrm{c}$ and $3 \mathrm{a}$, and is characterized by its great genetic diversity $[25,66]$. As may be seen in Figure 4 , these last three serotypes formed more biofilm than those in lineage I. Serotype 4a, which produced the greatest amount of biofilm in this study, belongs to lineage III. Serotype 4a has been isolated principally from ruminants and other non-primate mammals, and has not been linked to cases of human listeriosis $[25,77]$.

It is likely that the ability to form biofilms is linked to virulence genes, since in this investigation it was found that the more virulent a strain was the less able to form biofilm and vice versa. This same observation has been made by other authors $[23,79,80]$, who found increased formation of biofilm in strains of L. monocytogenes that had less virulence. The same hypothesis would explain why in this study the strain of L. ivanovii formed significantly more $(p<0.01)$ biofilm than the average for L. monocytogenes. It should be noted, however, that no virulence testing was performed in this research work. Moreover, the limited number of strains tested prevents any strong conclusions.

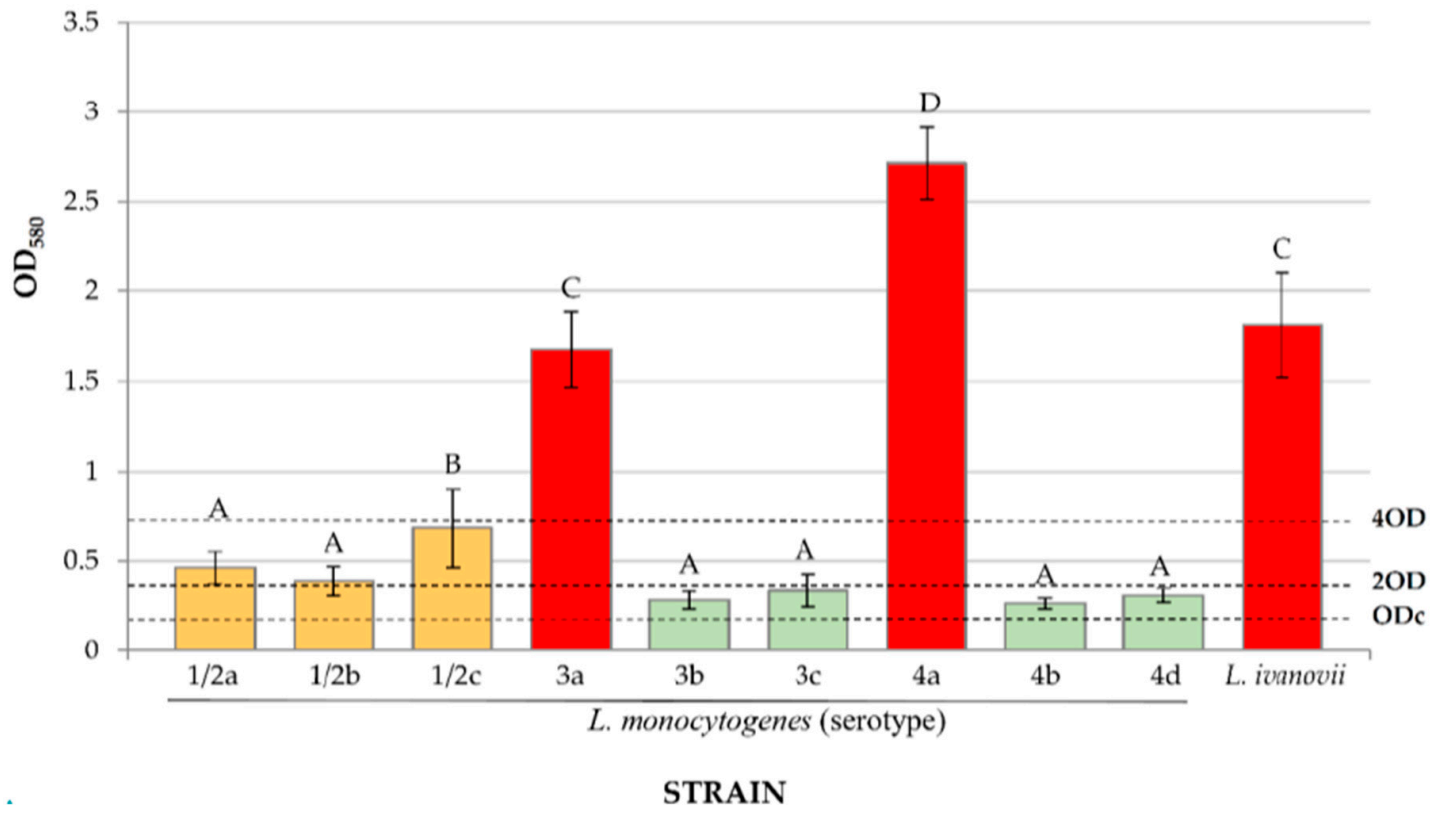

Figure 4. Biofilm formation by various strains of Listeria spp. on polystyrene after $24 \mathrm{~h}$ of incubation at $37^{\circ} \mathrm{C}$ (crystal violet staining technique; optical density at $580 \mathrm{~nm}$ ). Averages (mean \pm standard deviation; $n=6)$ with no letters in common are significantly different $(p<0.05)$. Strong producers of biofilm (OD > 4ODc); moderate producers of biofilm (2ODc $<$ OD $\leq 4 \mathrm{ODc}$ ); weak producers of biofilm (ODc $<$ OD $\leq$ 2ODc).

\section{Conclusions}

Of the L. monocytogenes strains from red meat and poultry that could be serotyped (87.3\%), the highest prevalence corresponded to serotypes $4 \mathrm{~b} / 4 \mathrm{e}$. This is troubling since serotype $4 \mathrm{~b}$ is the most frequently involved in outbreaks of human listeriosis. High levels of resistance to cephalosporins (cefoxitin, cefotaxime, cefepime), nalidixic acid, nitrofurantoin, and oxacillin were observed. It is true that $L$. monocytogenes presents intrinsic resistance to several of these antibiotics. However, in view of the seriousness of human listeriosis, the findings in this research make it advisable to set in place measures for monitoring and control that will permit any increase in the resistance to antibiotics of 
this bacterium to be avoided. Striking differences were noted in the growth parameters of the strains of Listeria as a function of species and serotype. The highest lag phase values were observed for serotypes $3 a, 3 b, 4 b$, and $4 d$ of L. monocytogenes, while the strain of serotype $1 / 2 b$ presented the shortest values for this kinetic parameter. The growth rate of the L. ivanovii strain tested here was greater than that of L. monocytogenes (average values). The results obtained highlighted an inverse relationship between the duration of the lag phase and the maximum density of bacteria in the stationary phase. The average time elapsed to stationary phase was $14 \mathrm{~h}$. The strains of L. monocytogenes studied were strong $(22.2 \%)$, moderate $(33.3 \%)$ or weak $(44.4 \%)$ biofilm producers. Listeria ivanovii showed a much greater capacity to form biofilm than did L. monocytogenes, a result that suggests an inverse relationship between virulence and ability to produce biofilm.

Author Contributions: Conceptualization, R.C. and C.A.-C.; Data Curation, R.C., C.G.-F. and C.A.-C.; Formal Analysis, R.C.; Funding Acquisition, R.C. and C.A.-C.; Investigation, R.C. and A.F.-M.; Methodology, R.C., A.F.-M., C.G.-F. and C.A.-C.; Project Administration, R.C. and C.A.-C.; Resources, R.C. and C.A.-C.; Software, C.A.-C.; Supervision, R.C. and C.A.-C.; Validation, A.F.-M., C.G.-F. and C.A.-C.; Visualization, R.C., A.F.-M., C.G.-F. and C.A.-C.; Writing-Original Draft Preparation, R.C.; Writing-Review \& Editing, R.C., C.G.-F. and C.A.-C.

Funding: This research was funded by the Ministerio de Ciencia, Innovación y Universidades (Spain, RTI2018-098267-R-C33) and the Junta de Castilla y León (Consejería de Educación, Spain, LE164G18).

Conflicts of Interest: The authors declare no conflict of interest.

\section{References}

1. Leclercq, A.; Moura, A.; Vales, G.; Tessaud-Rita, N.; Aguilhon, C. Listeria thailandensis sp. nov. Int. J. Syst. Microbiol. 2019, 69, 74-81. [CrossRef] [PubMed]

2. Herrador, Z.; Gherasim, A.; López-Vélez, R.; Benito, A. Listeriosis in Spain based on hospitalisation records, 1997 to 2015: Need for greater awareness. Eurosurveillance 2019, 24, 1800271. [CrossRef] [PubMed]

3. Ariza-Miguel, J.; Fernández-Natal, M.I.; Soriano, F.; Hernández, M.; Stessl, B.; Rodríguez-Lázaro, D. Molecular epidemiology of invasive listeriosis due to Listeria monocytogenes in a Spanish hospital over a nine-year study period, 2006-2014. BioMed Res. Int. 2015, 191409. [CrossRef]

4. Tan, M.F.; Siow, C.C.; Dutta, A.; Mutha, N.V.; Wee, W.Y.; Heydari, H.; Tan, S.Y.; Ang, M.Y.; Wong, G.J.; Choo, S.W. Development of ListeriaBase and comparative analysis of List. monocytogenes. BMC Genom. 2015, 16, 755-774. [CrossRef]

5. Donovan, S. Listeriosis: A rare but deadly disease. Clin. Microbiol. Newsl. 2015, 37, 135-141. [CrossRef]

6. Lomonaco, S.; Nucera, D.; Filipello, V. The evolution and epidemiology of Listeria monocytogenes in Europe and the United States. Infect. Genet. Evol. 2015, 35, 172-183. [CrossRef]

7. Parrilla, F.; Vaqué, J. Incidence study of listeriosis in Spain. Gac. Sanit. 2014, 28, 74-76. [CrossRef]

8. CDC. Listeria (Listeriosis). Centers for Disease Control and Prevention. Available online: https://www.cdc. gov/listeria/index.html (accessed on 20 September 2019).

9. EFSA; ECDC. The European Union summary report on trends and sources of zoonoses, zoonotic agents and food-borne outbreaks in 2017. EFSA J. 2018, 16, e05500. [CrossRef]

10. Cunha, S.; Komora, N.; Magalhaes, R.; Almeida, G.; Ferreira, V.; Teixeira, P. Characterization of clinical and food Listeria monocytogenes isolates with different antibiotic resistance patterns through simulated gastrointestinal tract conditions and environmental stresses. Microb. Risk Anal. 2016, 1, 40-46. [CrossRef]

11. Fallah, A.A.; Saei-Dehkordi, S.S.; Mahzounieh, M. Occurrence and antibiotic resistance profiles of Listeria monocytogenes isolated from seafood products and market and processing environments in Iran. Food Control 2013, 34, 630-636. [CrossRef]

12. Martín, B.; Perich, A.; Gómez, D.; Yangüela, J.; Rodríguez, A.; Garriga, M.; Aymerich, T. Diversity and distribution of Listeria monocytogenes in meat processing plants. Food Microbiol. 2014, 44, 119-127. [CrossRef] [PubMed]

13. Ragon, M.; Wirth, T.; Hollandt, F.; Lavenir, R.; Lecuit, M.; Le Monnier, A.; Brisse, S. A new perspective on Listeria monocytogenes evolution. PLoS Pathog. 2008, 4, e1000146. [CrossRef] [PubMed]

14. Jamshidi, A.; Zeinali, T. Significance and characteristics of Listeria monocytogenes in poultry products. Int. J. Food Sci. 2019, 7835253. [CrossRef] [PubMed] 
15. Wu, S.; Wu, Q.; Zhang, J.; Chen, M.; Yan, Z. Prevalence, antibiotic resistance and genetic diversity of Listeria monocytogenes isolated from retail ready-to-eat foods in China. Food Control 2015, 47, 340-347. [CrossRef]

16. Capita, R.; Alonso-Calleja, C. Antibiotic-resistant bacteria: A challenge for the food industry. Crit. Rev. Food Sci. Nutr. 2013, 53, 11-48. [CrossRef]

17. Komora, N.; Bruschi, C.; Magalhães, R.; Ferreira, V.; Teixeira, P. Survival of Listeria monocytogenes with different antibiotic resistance patterns to food-associated stresses. Int. J. Food Microbiol. 2017, 245, 79-87. [CrossRef]

18. Olaimat, A.N.; Al-Holy, M.A.; Shahbaz, H.M.; Al-Nabulsi, A.A.; Ghoush, M.H.A.; Osaili, T.M.; Ayyash, M.M.; Holley, R.A. Emergence of antibiotic resistance in Listeria monocytogenes isolated from food products: A comprehensive review. Compr. Rev. Food Sci. Food Saf. 2018, 17, 1277-1292. [CrossRef]

19. Gómez, D.; Azón, E.; Marco, N.; Carramiñana, J.J.; Rota, C.; Ariño, A.; Yangüela, J. Antimicrobial resistance of Listeria monocytogenes and Listeria innocua from meat products and meat-processing environment. Food Microbiol. 2014, 42, 61-65. [CrossRef]

20. Díez-García, M.; Capita, R.; Alonso-Calleja, C. Influence of serotype on the growth kinetics and the ability to form biofilms of Salmonella isolates from poultry. Food Microbiol. 2012, 31, 173-180. [CrossRef]

21. Rodríguez-Melcón, C.; Riesco-Peláez, F.; Carballo, J.; García-Fernández, C.; Capita, R.; Alonso-Calleja, C. Structure and viability of 24-and 72-h-old biofilms formed by four pathogenic bacteria on polystyrene and glass contact surfaces. Food Microbiol. 2018, 76, 513-517. [CrossRef]

22. Capita, R.; Riesco-Peláez, F.; Alonso-Hernando, A.; Alonso-Calleja, C. Exposure of Escherichia coli ATCC 12806 to sublethal concentrations of food-grade biocides influences its ability to form biofilm, resistance to antimicrobials, and ultrastructure. Appl. Environ. Microbiol. 2014, 80, 1268-1280. [CrossRef] [PubMed]

23. Piercey, M.J.; Hingston, P.A.; Hansen, L.T. Genes involved in Listeria monocytogenes biofilm formation at a simulated food processing plant temperature of $15^{\circ} \mathrm{C}$. Int. J. Food Microbiol. 2016, 223, 63-74. [CrossRef] [PubMed]

24. Pan, Y.; Breidt, F.; Gorski, L. Synergistic effects of sodium chloride, glucose, and temperature on biofilm formation by Listeria monocytogenes serotype 1/2a and 4b strains. Appl. Environ. Microbiol. 2010, 76, 1433-1441. [CrossRef] [PubMed]

25. Orsi, R.H.; Den Bakker, H.C.; Wiedmann, M. Listeria monocytogenes lineages: Genomics, evolution, ecology, and phenotypic characteristics. Int. J. Med Microbiol. 2011, 301, 79-96. [CrossRef] [PubMed]

26. Rothrock, M.; Micciche, A.C.; Bodie, A.R.; Ricke, S.C. Listeria occurrence and potential control strategies in alternative and conventional poultry processing and retail. Front. Sustain. Food Syst. 2019, 3, 33. [CrossRef]

27. CLSI. Performance Standards for Antimicrobial Disk Susceptibility Test; Approved Standard, 9th ed.; Clinical and Laboratory Standards Institute: Wayne, PA, USA, 2012.

28. Garthright, W.E. Refinements in the prediction of microbial growth curves. Food Microbiol. 1991, 8, $239-248$. [CrossRef]

29. Iannetti, L.; Acciari, V.A.; Antoci, S.; Addante, N.; Bardasi, L.; Bilei, S.; Calistri, P.; Cito, F.; Cogoni, P.; D'Aurelio, R.; et al. Listeria monocytogenes in ready-to-eat foods in Italy: Prevalence of contamination at retail and characterization of strains from meat products and cheese. Food Control 2016, 68, 55-61. [CrossRef]

30. Bille, J.; Rocourt, J. WHO International multicenter Listeria monocytogenes subtyping study-rationale and set-up of the study. Food Microbiol. 1996, 32, 251-262. [CrossRef]

31. Kérouanton, A.; Marault, M.; Petit, L.; Grout, J.; Dao, T.T.; Brisabois, A. Evaluation of a multiplex PCR assay as an alternative method for Listeria monocytogenes serotyping. J. Microbiol. Methods 2010, 80, 134-137. [CrossRef]

32. Low, J.C.; Donachie, W. Clinical and serum antibody responses of lambs to infection by Listeria monocytogenes. Res. Vet. Sci. 1991, 5, 185-192. [CrossRef]

33. Palumbo, J.D.; Boruchi, M.K.; Mandrell, R.E.; Gorski, L. Serotyping of Listeria monocytogenes by enzyme-linked immunosorbent assay and identification of mixed-serotype cultures by colony immunoblotting. J. Clin. Microbiol. 2003, 41, 564-571. [CrossRef] [PubMed]

34. Scönberg, A.; Bannerman, E.; Courtieu, A.L.; Kiss, R.; McLauchlin, J.; Shah, S.; Wilhelms, D. Serotyping of 80 strains from the WHO multicentre international typing study of Listeria monocytogenes. Int. J. Food Microbiol. 1996, 32, 279-287. [CrossRef] 
35. Leclercq, A.; Chenal-Francisque, V.; Dieye, H.; Cantinelli, T.; Drali, R.; Brisse, S.; Lecuit, M. Characterization of the novel Listeria monocytogenes PCR serogrouping profile IVb-v1. Int. J. Food Microbiol. 2011, 147, 74-77. [CrossRef] [PubMed]

36. Wang, Y.; Zhao, A.; Zhu, R.; Lan, R.; Jin, D.; Cui, Z.; Wang, Y.; Li, Z.; Wang, Y.; Xu, J.; et al. Genetic diversity and molecular typing of Listeria monocytogenes in China. BMC Microbiol. 2012, 12, 119-128. [CrossRef] [PubMed]

37. Ciolacu, L.; Nicolau, A.I.; Wagner, M.; Rychli, K. Listeria monocytogenes isolated from food samples from a Romanian black market show distinct virulence profiles. Int. J. Food Microbiol. 2015, 209, 44-51. [CrossRef] [PubMed]

38. Ebner, R.; Stephan, R.; Althaus, D.; Brisse, S.; Maury, M.; Tasara, T. Phenotypic and genotypic characteristics of Listeria monocytogenes strains isolated during 2011-2014 from different food matrices in Switzerland. Food Control 2015, 57, 321-326. [CrossRef]

39. Korsak, D.; Borek, A.; Daniluk, S.; Grabowska, A.; Pappelbaum, K. Susceptibilities of Listeria monocytogenes strains isolated from food and food processing environment in Poland. Int. J. Food Microbiol. 2012, 158, 203-208. [CrossRef]

40. Kramarenko, T.; Roasto, M.; Meremae, K.; Kuningas, M.; Poltsama, P.; Elias, T. Listeria monocytogenes prevalence and serotype diversity in various foods. Food Control 2013, 30, 24-29. [CrossRef]

41. Prencipe, V.A.; Rizzi, V.; Acciari, V.; Iannetti, L.; Giovannini, A.; Serraino, A.; Calderone, D.; Rossi, A.; Morelli, D.; Marino, L.; et al. Listeria monocytogenes prevalence, contamination levels and strains characterization throughout the Parma ham processing chain. Food Control 2012, 25, 150-158. [CrossRef]

42. Yu, T.; Jiang, X. Prevalence and characterization of Listeria monocytogenes isolated from retail food in Henan, China. Food Control 2014, 37, 228-231. [CrossRef]

43. Meloni, D.; Galluzzo, P.; Mureddu, A.; Piras, F.; Griffiths, M.; Mazette, R. Listeria monocytogenes in RTE foods marketed in Italy: Prevalence and automated EcoRI ribotyping of the isolates. Int. J. Food Microbiol. 2009, 129, 166-173. [CrossRef] [PubMed]

44. Vasilev, V.; Japheth, R.; Breuer, R.; Andom, N.; Abraham, R.B.; Yoni, Y.; Valinsky, L.; Agmon, V. A survey of Listeria monocytogenes strains, isolated from ready-to-eat foods in Israel over a period of 10 years, 1998-2007. Food Control 2010, 21, 1179-1181. [CrossRef]

45. Martins, E.A.; Germano, P.M.L. Listeria monocytogenes in ready-to-eat, sliced, cooked ham and salami products, marketed in the city of São Paulo, Brazil: Occurrence, quantification, and serotyping. Food Control 2011, 22, 297-302. [CrossRef]

46. Fallah, A.A.; Saei-Dehkordi, S.S.; Rahnama, M.; Tahmasby, H.; Mahzounieh, M. Prevalence and antimicrobial resistance patterns of Listeria species isolated from poultry products marketed in Iran. Food Control 2012, 28, 327-332. [CrossRef]

47. Notification Details-2019.2989. Foodborne Outbreak Caused by Listeria monocytogenes (>1.5x10E4 CFU/g) in Chilled Pork Products from Spain. Available online: https://webgate.ec.europa.eu/rasff-window/portal/ ?event=notificationDetail\&NOTIF_REFERENCE=2019.2989 (accessed on 20 September 2019).

48. Junta de Andalucía. Consejería de Salud y Familias. Available online: https://www.juntadeandalucia.es/ organismos/saludyfamilias/actualidad/noticias/detalle/220344.html (accessed on 20 September 2019).

49. Alonso-Hernando, A.; Prieto, M.; García-Fernández, C.; Alonso-Calleja, C.; Capita, R. Increase over time in the prevalence of multiple antibiotic resistance among isolates of Listeria monocytogenes from poultry in Spain. Food Control 2012, 23, 37-41. [CrossRef]

50. Adzitey, F.; Ali, G.R.R.; Huda, N.; Cogan, T.; Corry, J. Prevalence, antibiotic resistance and genetic diversity of Listeria monocytogenes isolated from ducks, their rearing and processing environments in Penang, Malaysia. Food Control 2013, 32, 607-614. [CrossRef]

51. Bae, D.; Mezal, E.H.; Smiley, R.D.; Cheng, C.-M.; Khan, A.A. The sub-species characterization and antimicrobial resistance of Listeria monocytogenes isolated from domestic and imported food products from 2004 to 2011. Food Res. Int. 2014, 64, 656-663. [CrossRef]

52. Doménech, E.; Jimenez-Belenguer, A.; Amoros, J.A.; Ferrus, M.A.; Escriche, I. Prevalence and antimicrobial resistance of Listeria monocytogenes and Salmonella strains isolated in ready-to-eat foods in Eastern Spain. Food Control 2015, 47, 120-125. [CrossRef] 
53. Wang, X.-M.; Lü, X.-F.; Yin, L.; Liu, H.-F.; Zhang, W.-J.; Si, W.; Tu, S.-Y.; Shao, M.-L.; Liu, S.-G. Occurrence and antimicrobial susceptibility of Listeria monocytogenes isolates from retail raw foods. Food Control 2013, 32, 153-158. [CrossRef]

54. WHO. Critically Important Antimicrobials for Human Medicine, 6th ed.; World Health Organization: Geneva, Switzerland, 2019.

55. OIE. OIE List of Antimicrobial agents of Veterinary Importance; World Organization for Animal Health: Paris, France, 2018.

56. Romanova, N.A.; Wolffs, P.F.G.; Brovko, L.Y.; Griffiths, M.W. Role of efflux pumps in adaptation and resistance of Listeria monocytogenes to benzalkonium chloride. Appl. Environ. Microbiol. 2006, 72, 3498-3503. [CrossRef]

57. Mata, M.T.; Baquero, F.; Pérez-Díaz, J.C. A multidrug efflux transporter in Listeria monocytogenes. FEMS Microbiol. Lett. 2000, 187, 185-188. [CrossRef] [PubMed]

58. Hernando-Amado, S.; Blanco, P.; Alcalde-Rico, M.; Corona, F.; Reales-Calderón, J.A.; Sánchez, M.B.; Martínez, J.L. Multidrug efflux pumps as main players in intrinsic and acquired resistance to antimcirobials. Drug Resist. Updates 2016, 28, 13-27. [CrossRef] [PubMed]

59. Marian, M.N.; Aminah, S.M.; Zuraini, M.I.; Son, R.; Maimunah, M.; Lee, H.Y.; Wong, W.C.; Elexson, N. MPN-PCR detection and antimicrobial resistance of Listeria monocytogenes isolated from raw and ready-to-eat foods in Malaysia. Food Control 2012, 28, 309-314. [CrossRef]

60. Augustin, J.-C.; Rosso, L.; Carlier, V. Estimation of temperature dependent growth rate and lag time of Listeria monocytogenes by optical density measurements. J. Microbiol. Methods 1999, 38, 137-146. [CrossRef]

61. Magalhães, R.; Ferreira, V.; Brandão, T.R.S.; Palencia, R.C.; Almeida, G.; Teixeira, P. Persistent and non-persistent strains of Listeria monocytogenes: A focus on growth kinetics under different temperature, salt, and $\mathrm{pH}$ conditions and their sensitivity to sanitizers. Food Microbiol. 2016, 57, 103-108. [CrossRef] [PubMed]

62. Robinson, T.P.; Aboaba, O.O.; Kaloti, A.; Ocio, M.J.; Baranyi, J.; Mackey, B.M. The effect of inoculum size on the lag phase of Listeria monocytogenes. Int. J. Food Microbiol. 2001, 70, 163-173. [CrossRef]

63. Tsai, H.N.; Hodgson, D.A. Development of a synthetic minimal medium for Listeria monocytogenes. Appl. Environ. Microbiol. 2003, 69, 6943-6945. [CrossRef]

64. Vialette, M.; Pinon, A.; Chasseignaux, E.; Lange, M. Growths kinetics comparison of clinical and seafood Listeria monocytogenes isolates in acid and osmotic environment. Int. J. Food Microbiol. 2003, 82, 121-131. [CrossRef]

65. Sant'Ana, A.S.; Franco, B.; Schaffner, D.W. Modeling the growth rate and lag time of different strains of Salmonella enterica and Listeria monocytogenes in ready-to-eat lettuce. Food Microbiol. 2012, 30, 267-273. [CrossRef]

66. Xuan, X.-T.; Ding, T.; Li, J.; Ahn, J.-H.; Zhao, Y.; Chen, S.-G.; Ye, X.-Q.; Liu, D.-H. Estimation of growth parameters of Listeria monocytogenes after sublethal heat and slightly acidic electrolyzed water (SAEW) treatment. Food Control 2017, 71, 17-25. [CrossRef]

67. Jarvis, N.A.; O’Bryan, C.A.; Ricke, S.C.; Johnson, M.G.; Crandall, P.G. A review of minimal and defined media for growth of Listeria monocytogenes. Food Control 2016, 66, 256-269. [CrossRef]

68. Lianou, A.; Stopforth, J.D.; Yoon, Y.; Wiedmann, M.; Sofos, J.N. Growth and stress resistance variation in culture broth among Listeria monocytogenes strains of various serotypes and origins. J. Food Prot. 2006, 69, 2640-2647. [CrossRef]

69. Mytilinaios, I.; Salih, M.; Schofield, H.K.; Lambert, R.J.W. Growth curve prediction from optical density data. Int. J. Food Microbiol. 2012, 154, 169-176. [CrossRef] [PubMed]

70. Aguirre, J.S.; González, A.; Özçelik, N.; Rodríguez, M.R.; García de Fernando, G. Modeling the Listeria innocua micropopulation lag phase and its variability. Int. J. Food Microbiol. 2013, 164, 60-69. [CrossRef] [PubMed]

71. Rodríguez-Melcón, C.; Capita, R.; Rodriguez-Jerez, J.J.; Martínez-Suárez, J.V.; Alonso-Calleja, C. Effect of low doses of disinfectants on the biofilm-forming ability of Listeria monocytogenes. Foodborne Pathog. Dis. 2019, 16, 262-268. [CrossRef] [PubMed]

72. Rodríguez-Melcón, C.; Riesco-Peláez, F.; García-Fernández, C.; Alonso-Calleja, C.; Capita, R. Susceptibility of Listeria monocytogenes planktonic cultures and biofilms to sodium hypochlorite and benzalkonium chloride. Food Microbiol. 2019, 82, 533-540. [CrossRef] [PubMed] 
73. Kadam, S.R.; Den Besten, H.M.W.; Dan Der Veen, S.; Zwietering, M.H.; Moezelaar, R.; Abee, T. Diversity assessment of Listeria monocytogenes biofilm formation: Impact of growth condition, serotype and strain origin. Int. J. Food Microbiol. 2013, 165, 259-264. [CrossRef]

74. Nilsson, R.E.; Ross, T.; Bowman, J.P. Variability in biofilm production by Listeria monocytogenes correlated to strain origin and growth conditions. Int. J. Food Microbiol. 2011, 150, 14-24. [CrossRef]

75. Nyenje, M.E.; Green, E.; Ndip, R.N. Biofilm formation and adherence characteristics of Listeria ivanovii strains isolated from ready-to-eat roods in Alice, South Africa. Sci. World J. 2012, 873909. [CrossRef]

76. Eskhan, A.O.; Abu-Lail, N.I. Cellular and molecular investigations of the adhesion and mechanics of Listeria monocytogenes lineages' I and II environmental and epidemic strains. J. Colloid Interface Sci. 2013, 394, 554-563. [CrossRef]

77. Tsai, Y.-H.L.; Maron, S.B.; McGann, P.; Nightingale, K.K.; Wiedmann, M.; Orsi, R.H. Recombination and positive selection contributed to the evolution of Listeria monocytogenes lineages III and IV, two distinct and well supported uncommon L. monocytogenes lineages. Infect. Genet. Evol. 2011, 11, 1881-1890. [CrossRef] [PubMed]

78. Paul, D.; Steele, C.; Donaldon, J.R.; Banes, M.M.; Kumar, R.; Bridges, S.M.; Arick, M.; Lawrence, M. Genome comparison of Listeria monocytogenes serotype 4a strain HCC23 with selected lineage I and lineage II L. monocytogenes strains and other Listeria strains. Genom. Data 2014, 2, 219-225. [CrossRef] [PubMed]

79. Franciosa, G.; Maugliani, A.; Scalfaro, C.; Floridi, F.; Aureli, P. Expression of internalin A and biofilm formation among Listeria monocytogenes clinical isolates. Int. J. Immunopathol. Pharm. 2009, 22, 183-193. [CrossRef] [PubMed]

80. Kovacevic, J.; Arguedas-Villa, C.; Wozniak, A.; Tasara, T.; Allen, K.J. Examination of food chain-derived Listeria monocytogenes strains of different serotypes reveals considerable diversity in inlA genotypes, mutability, and adaptation to cold temperatures. Appl. Environ. Microbiol. 2013, 79, 1915-1922. [CrossRef]

(C) 2019 by the authors. Licensee MDPI, Basel, Switzerland. This article is an open access article distributed under the terms and conditions of the Creative Commons Attribution (CC BY) license (http://creativecommons.org/licenses/by/4.0/). 